\title{
A developmental and training study of children's ability to find safe routes to cross the road
}

\author{
K. Ampofo-Boateng and J. A. Thomson* \\ Department of Psycbology, University of Strathclyde, Alexander Turnbull Building, 155 George Street, \\ Glasgow G1 1RD, Scotland
}

\author{
R. Grieve, T. Pitcairn, D. N. Lee and J. D. Demetre \\ Department of Psychology, University of Edinburgh
}

\begin{abstract}
The sites and routes that children of different ages considered to be safe to cross the road were investigated. In Expt 1, children aged 5, 7,9 and 11 years were instructed to choose 'the safest' crossing sites and routes to specified destinations. The results showed a gradual developmental shift with safer, more adult-like choices appearing with increasing age. Five- and 7-year-olds exhibited only a rudimentary selection procedure, choosing the most direct route as safest and showing a marked lack of procedure, choosing the most dist restrictions. In a further experiment, 5-year-olds were individually trained in finding safe places to cross. Training took place either in the real road environment or using a tabletop model of a traffic environment. A series of pre- and post-tests enabled the effectiveness of the training to be assessed. Substantial improvements following training were obtained in both groups. No differences were found between the two training methods. Though performance fell somewhat over the two months following training, trained children still outperformed their untrained peers eight months after the programme ended. The implications for road safety education are discussed.
\end{abstract}

Road accidents constitute one of the most serious health problems facing young children in the modern world (Deschamps, 1981). In 1987, for example, over 2300 child pedestrians aged between 5 and 9 years were killed or seriously injured, representing a casualty rate four times that of adults (O'Donoghue, 1988). When the relatively low exposure of children to traffic is taken into account, this disparity becomes even more pronounced (Routledge, Repetto-Wright \& Howarth, 1974).

The marked vulnerability of children relative to older pedestrians must be largely due to lack of skill, particularly in view of their much lower exposure to risk. Not surprisingly, most countries have developed some form of road safety education in 


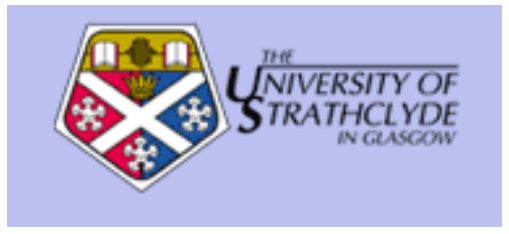

Jahan, M.K. and Paterson, A. and Piggott, J.R. and Spickett, C.M. (2005) Chemometric modelling to relate antioxidants, neutral lipid fatty acids and flavour components in chicken breast. Poultry Science, 84 (1). pp. 158-166. ISSN 0032-5791

http://strathprints.strath.ac.uk/8401/

This is an author produced version of a paper published in Poultry Science, 84 (1). pp. 158-166. ISSN 0032-5791. This version has been peer-reviewed but does not include the final publisher proof corrections, published layout or pagination.

Strathprints is designed to allow users to access the research output of the University of Strathclyde. Copyright ( $)$ and Moral Rights for the papers on this site are retained by the individual authors and/or other copyright owners. You may not engage in further distribution of the material for any profitmaking activities or any commercial gain. You may freely distribute both the url (http://strathprints.strath.ac.uk) and the content of this paper for research or study, educational, or not-for-profit purposes without prior permission or charge. You may freely distribute the url (http://strathprints.strath.ac.uk) of the Strathprints website.

Any correspondence concerning this service should be sent to The Strathprints Administrator: eprints@cis.strath.ac.uk 
an effort to combat these trends (see Gardner, Rowley, Bowen, Hayman \& Fyfield, 1986).

Most current techniques, such as the British Green Cross Code, tackle the problem by providing a conceptual framework together with a simple strategy intended to be applicable to a wide variety of situations (Dean, 1981). Such strategies have been widely publicized and taught for many years and have become the mainstay of road safety education in this and most countries (Ampofo-Boateng \& Thomson, 1990). Unfortunately, the success rate of such measures appears far from inspiring. Few authorities would claim that they have reduced accidents by more than 10 per cent, which is hardly an impressive record given the scale of the problem (Howarth \& Repetto-Wright, 1978).

How might we explain the relative ineffectiveness of educational programmes? One suggestion that has proved extremely influential is that young children, by virtue of their age and stage of psychological development, simply are not capable of acquiring the skills needed to cope with the traffic environment. One of the earliest proponents of this point of view was Sandels (1975), whose extensive and influential pioneering work on child pedestrian behaviour in Sweden led her to the conclusion that '... it is not possible to adapt fully young children (under 10 years) to the traffic environment. They are biologically incapable of managing its many demands' (Sandels, 1975).

This appears to be a pseudo-Piagetian position in that it is assumed the perceptual and cognitive capacities required for traffic participation must follow a fixed, agedetermined path. The assumption is important because, if true, it would imply that there is only a limited amount that can be achieved with younger children through education or training. This would shift the emphasis in road safety away from education altogether to other areas such as engineering and urban design. The view has gained many adherents and appears to underlie much current thinking in road safety (see van der Molen, 1983; Thomson, 1991; Tight, 1991).

Is this pessimistic outlook with regard to education entirely justified? An alternative possibility is that current educational measures fail simply because they do not teach what children really need to know in order to deal safely with traffic. We and others have recently drawn attention to the fact that current countermeasures are seldom founded on a proper analysis of the skills required to deal with the road environment (Ampofo-Boateng \& Thomson, 1990; Lee, Young \& McLaughlin, 1984; Thomson, 1991). Indeed, the question as to what are the proper skills to teach has not been addressed. In fact, most measures do not attempt to teach skills at all but rather concentrate on the acquisition of knowledge and appropriate attitudes towards road safety. Unfortunately, numerous studies have shown that knowledge and attitudes acquired in the classroom do not transfer readily to behaviour at the roadside (e.g. Rothengatter, 1981a; Vinje, 1981). This is probably because pedestrians need procedural rather than declarative knowledge and the former is not readily acquired through verbal methods. Therefore, a possible reason for the failure of current methods is not that children are inherently incapable of acquiring the requisite skills until some biologically determined point is reached; but that these skills are neither recognized nor taught by current educational methods.

Recent studies that have concentrated on clearly defined skills have produced 
encouraging results for road safety education. For example, Lee $e t$ al. (1984) have drawn attention to the visual timing skills that a pedestrian needs in judging whether there is time to cross the road before an approaching vehicle arrives. This would seem to involve perceiving the time to arrival of an approaching vehicle; the time required to cross the road in question; and the ability to relate the two. Such visual timing skills appear to be poorly developed in young children but can be improved through practical roadside training (Young \& Lee, 1987). The findings suggest that it might indeed be possible to teach key pedestrian skills to children (as young as 5 years in the case of Young \& Lee's subjects), making them behave like older, more experienced pedestrians. Whether this is achieved, however, depends on recognizing the skill that is required in the first place and then finding appropriate methods to teach it.

A skill to which we have recently drawn attention that has also not been adequately recognized is the ability to identify dangerous situations on the road where crossing should not be attempted or where special strategies are required (Ampofo-Boateng \& Thomson, 1991). The Green Cross Code does not emphasize this skill, merely instructing children to 'first find a safe place'. This, of course, assumes that they can do so. In a number of studies, we have shown that children under the age of about 9 years are very poor at recognizing dangerous places or at finding safer ones. Young children assume most sites are safe provided no cars are visible nearby. Thus blind corners, sharp bends or positions where the road is masked by obstacles are typically regarded as safe places to cross. Only around 9 years do children begin to appreciate the intrinsic dangers posed by such sites and begin developing strategies for dealing with them (Ampofo-Boateng \& Thomson, 1991).

This weakness in perceiving the intrinsic danger of road sites and structures corresponds rather well to children's accident data. For example, our own analyses of accident patterns in Glasgow consistently identified bends, intersections, obstructions, the brow of hills and similar locations as overrepresented in child pedestrian accidents (Ampofo-Boateng, 1987). The common characteristics of the sites seemed to be either that visibility was restricted at the locations concerned; or else that traffic might approach from several directions, taxing the child's attention and informationprocessing capacities (Thomson, 1991). Similar patterns have been identified by other authors (e.g. van der Molen, 1983). The correspondence between accident data and the child's skills suggests a possible causal relationship that should be treated seriously. Certainly, the child's inability to recognize the danger of such sites can hardly be described as advantageous to his safety.

These findings identify a potentially serious shortcoming of current road safety training which concentrates almost exclusively on the road crossing task. However, the ability to find a safe place is an essential precursor to the act of crossing because if children attempt to do so on the brow of a hill they will be in considerable danger no matter how attentive they are or how well they have learned the mechanics of the Green Cross Code. Teaching children how to find safe sites is, therefore, a crucial problem for road safety education that has not received the recognition it deserves.

In the present study, we examine the extent to which young children can be trained to choose safe sites and routes to cross the road. We also include a developmental 
study so that the skills of young children after training can be compared to the skills of older, more experienced pedestrians. Can the skills of young children be accelerated, making them behave like older, more mature pedestrians or must their development follow a predetermined path? If they can be taught, what kind of training programme is likely to be effective in doing so? The following experiments were designed to answer these questions.

\section{EXPERIMENT 1}

To identify developmental trends and to provide baseline measures against which the effects of training might be assessed, we tested children aged 5, 7,9 and 11 years on their ability to choose safe places to cross the road. All testing was conducted in the real road environment in streets near the children's school.

\section{Method}

\section{Subjects}

Four age groups each comprising 10 subjects were tested. Each group contained an equal number of boys and girls. The mean ages of each group were: 5 years 5 months; 7 years 8 months; 9 years 9 months and 11 years 8 months. The subjects were randomly selected from a sample of primary schoolchildren whose parents had consented to their participation in the study.

\section{Procedure}

The children were taken individually from their classroom at the convenience of their teachers and tested at the roadside. The sites were all close to a fairly busy two-lane road with a speed limit of $30 \mathrm{~m}$.p.h. $(48 \mathrm{~km} / \mathrm{h})$. The actual locations were spread out on roads in the nearby vicinity. All were within walking distance of the school, ensuring that the time taken to get to the test sites was not too long. Four test locations were selected, consisting of three where visibility was restricted and one where traffic might emerge from several directions (a junction). These locations were selected in accordance with previous findings suggesting that young children fail to appreciate the danger posed there (Ampofo-Boateng \& Thomson, 1991).

At each location the children were instructed by the experimenter to imagine they were on their own and wanted to cross the road to a destination on the other side. Each destination was indicated by a red cone $(32 \mathrm{~cm}$ high) of the type used by police for traffic control. The child's task was to select the safest way to get there. At each location there were two destinations and two separate starting points. Thus each child had to choose four separate routes at each of the four locations, making 16 routes per test session. Each child was tested on three separate days, yielding a total of 48 constructed routes per child. An example of one test site is illustrated in Fig. 1.

The children indicated their preferred routes simply by pointing and describing it to the experimenter. They were never asked to actually walk across the road. Each chosen route was recorded on to a scale schematic drawing which incorporated numerous landmarks and reference points to ensure accuracy of detail. In the few cases where it was difficult to ascertain precisely what path the child would take, referring to these landmarks helped determine the route the child wished to select. The diagram was updated at the beginning of each session to take account of changing conditions. Scoring was thus based on the conditions actually prevalent at the time. 


\section{Scoring}

The routes chosen by the children were coded into four safety categories, depending on the degree to which dangerous road features were avoided in the chosen route. These categories were derived empirically from the patterns that emerged in the children's choice of safe routes. The four categories, running from minimum to maximum safety awareness, were as follows:

1. Very unsafe. A route leading directly to the destination (often involving a long, diagonal traverse of the road), that also ignored the dangerous road features at which the starting point was located (e.g. a parked car).

2. Unsafe. A straight route across the road not aimed directly at the destination but which ignored dangerous road features. This was an improvement on (1) because it at least reduced the time spent on the road.

3. More safe. A route avoiding some but not all dangerous road features. This usually occurred when the child made a detour away from a dangerous position (for example, moving down the road away from a parked car) but ended up at a new spot which might also be dangerous (for example, at a sharp bend). 4. Safe. A route which avoided all the dangerous road configurations. This often involved walking along the pavement and crossing only when a safe site was found.

To assess the reliability of the ratings, a 25 per cent sample of the protocols was selected and independently coded by a second rater. Inter-rater reliability was .89 . Examples of the categories are shown in Fig. 1.

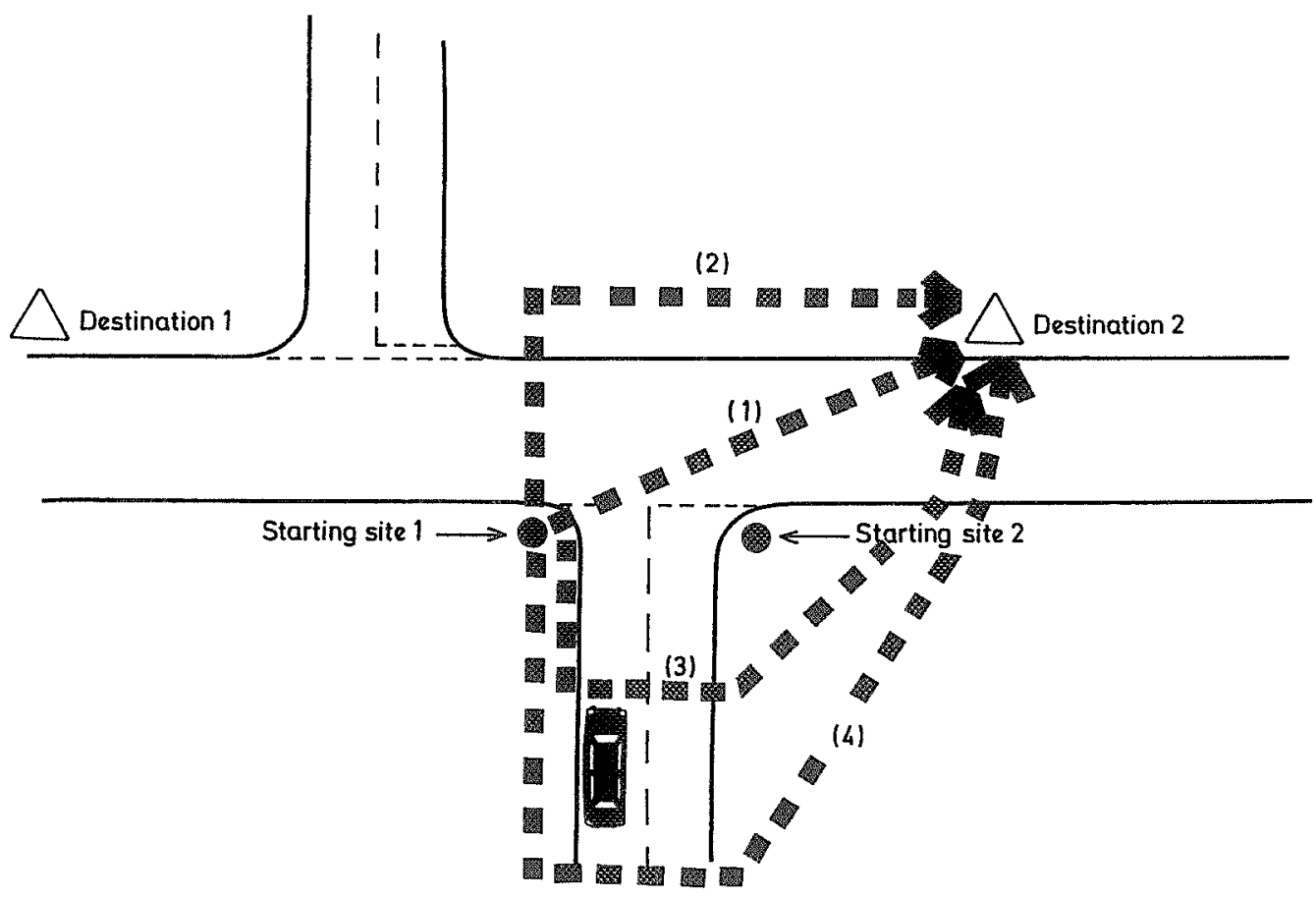

Figure 1. One of the sites used in the study. The arrows show examples of the routes children might construct from (1) very unsafe to (4) safe. 


\section{Results}

For each child, we calculated the mean proportion of routes falling into each of the four safety categories. We then calculated the mean proportion of routes falling into each safety category for each age group. Table 1 shows the result of this analysis. The same procedure was followed in analysing the effects of sex but, since this produced neither a main effect nor an interaction with age in the statistical analysis (see Table 1), it has been excluded from the table.

Table 1. Mean proportion of routes falling into each safety category by age (standard deviations in parentheses)

\begin{tabular}{lcccc}
\hline & \multicolumn{5}{c}{ Age (years) } \\
\cline { 2 - 5 } Safety category & 5 & 7 & 9 & 11 \\
\hline Very unsafe & .50 & .15 & .02 & .00 \\
& $(.29)$ & $(.29)$ & $(.04)$ & $(.00)$ \\
Unsafe & .33 & .60 & .36 & .24 \\
& $(.27)$ & $(.28)$ & $(.27)$ & $(.21)$ \\
More safe & .09 & .07 & .05 & .00 \\
& $(.12)$ & $(.10)$ & $(.03)$ & $(.01)$ \\
Safe & .10 & .21 & .56 & .75 \\
& $(.15)$ & $(.20)$ & $(.28)$ & $(.20)$ \\
\hline
\end{tabular}

It can be seen that most 5 -year-olds selected routes which were either unsafe or very unsafe, whilst the 7 -year-olds chose primarily unsafe routes. Nine- and especially 11 -year-olds on the other hand, chose a far larger number of routes falling into the 'more safe' or 'safe' categories.

Statistical analysis of these trends was based on the proportion of routes that fell into the 'safe' category for each age group; that is, the proportion that reached the criterion of being adequately safe had the children been permitted to actually cross the road. A two-way analysis of variance (ANOVA) yielded a main effect of age $(F(3,32)=24.27, p<.001)$ but not of sex. There was no interaction. Post hoc comparisons using the Newman-Keuls test showed significant differences between each age group, with the younger groups constructing fewer safe routes in every case $(p<.01$ in all cases).

\section{Discussion}

Experiment 1 examined the ability of children of different ages to choose safe routes across the road. The findings demonstrate that children's ability to do this changes quite markedly with age. Five- and 7-year-olds demonstrated very limited awareness of the dangers inherent in such crossing locations, seldom realizing that obstructions blocking their visibility (and also making them hard for others to see) were 
dangerous and should be avoided. Similarly, they did not appear to appreciate the dangers posed by crossing at junctions where traffic might appear from several directions. Indeed, in many cases the youngest children thought the safest strategy was to walk directly to the destination. This often meant walking diagonally across the road (thereby spending a lot of time on it) but at the junction it meant walking right out across the whole configuration, thereby exposing the children to traffic from every direction! By contrast, the 9-and 11-year-olds showed far more awareness of what constitutes a safe or dangerous route and were much more likely to take appropriate action to reduce the risk, for example by moving down the road to a safer spot.

Two further findings are worth noting at this point. Firstly, the changes that took place with age seemed almost to constitute a change of strategy. Five-year-olds' strategy is essentially to make directly for the target, moving diagonally across the road or junction if necessary. In general, they were happy to walk straight out from next to a parked car or other obstruction, quite failing to see the danger of this. By 7 years, the children seem much more likely to walk straight across the road, apparently realizing the danger of the longer diagonal. However, they were still unlikely to recognize the danger posed by obstructions to their vision. Moreover, in a proportion of the cases where they did, the action they took to deal with the problem led them to a new location that was also dangerous (category 3 responses). Only by 9 and especially 11 years do children seem to have developed some skill in recognizing the danger of inadequate vision of the road and adopt a successful strategy to overcome it.

These findings are very close to those previously reported by Ampofo-Boateng \& Thomson (1991). In that study, we observed that 5- and 7-year-olds' judgements of danger were very heavily determined by whether or not they could see a car in the vicinity. If they could see a vehicle from their current pusition, they alınost always judged the site as dangerous. This sometimes meant vehicles which were so far away as to be scarcely visible at all or even, in some cases, vehicles moving in the opposite direction! Conversely, if no vehicles were present in their field of view they would judge the site to be a safe one. Thus, brows of hills, sharp bends or positions obscured by vehicles were all regarded as satisfactory crossing points by most 5 - and 7-year-olds. The children did not seem to realize that these sites were dangerous precisely because they could not see any vehicles. Younger children's road behaviour appeared to be governed by rather rigid rules of thumb such as 'do not cross if you see a car coming'. The present study suggests they also interpret the common advice to 'go straight across the road' very rigidly as well, making straight for the destination and showing reluctance to choose a more circuitous, but safer, route. The present findings, then, appear to confirm the insensitivity to such dangers even in tests conducted exclusively in the real road environment and in an area that was broadly familiar to the children concerned.

A further finding is the lack of any sex difference in the proportion of safe routes that were selected. In spite of the marked sex differences in child pedestrian casualty rates, it appears these cannot be explained through differences in the skills examined here. In view of the considerable difficulty in identifying any factors that might satisfactorily account for sex differences in accident rates (see for example, Foot, 
1985; Thomson, 1991), this should perhaps not surptise us. It is an extremely puzzling anomaly that deserves careful analysis.

Our results clearly identify an important aspect of young children's traffic behaviour that needs improvement. This leads us to the question of whether a method might be found to develop this aspect of good road behaviour. We have already noted the controversy as to whether or not such skills can be accelerated in young children. One finding that leads us to take an optimistic view is that, even amongst our 5- and 7-year-olds, we did find one or two children behaving like much older, more experienced pedestrians. Whilst the effect was limited to a small proportion of the children, this nevertheless suggests that children may not be psychologically incapable of accelerated learning of such skills as some writers have assumed (e.g. Howarth \& Repetto-Wright, 1978; Sandels, 1975; Singh, 1982). In Expt 2, then, we assess two training methods which were designed to assist the most vulnerable children (5-year-olds) to improve their ability to find safe routes, with the aim of making them behave like older, more experienced children.

\section{EXPERIMENT 2}

The two training methods were: (1) roadside training in the real traffic environment and (2) using a tabletop model of the traffic environment. There is much evidence that road safety programmes using the actual traffic environment are more effective than programmes using other instructional situations (Rothengatter, 1984a,b). However, in assessing the effectiveness of the tabletop model as a training tool, we were encouraged by a recent study by van Schagen \& Rothengatter (1986) who used a tabletop model to train first graders (aged about 6 years) to cross at an intersection. The results when compared to those of children trained in real traffic showed a similar magnitude of effect in both groups. These results contradict Rothengatter's earlier (1981b) conclusion that young children are incapable of generalizing from models to real traffic conditions. The potential of such models seems to depend on the skills they are trying to teach. Two questions are thus addressed in the present experiment. (1) Can children be trained to select safer routes to cross the road? (2) How does training with a tabletop model compare to training in the real traffic environment?

\section{Method}

\section{Subjects}

Two groups of eight children whose parents had agreed to their participation were tandomly selected from the Primary 1 class of an Edinburgh school. One group trained using the tabletop model while the other was trained in the real traffic environment. The groups were balanced for sex. The mean ages were: tabletop model group: 5 years 6 months; teal traffic group: 5 years 5 months.

\section{Setting}

Tabletop model group members were trained in a school classroom. The model consisted of a large base (approx $120 \times 100 \mathrm{~cm}$ ) made from hardboard on to which a layout of roads had been constructed. A 
range of buildings, trees, hedges and other 'fumiture' was used to construct a traffic environment and toy cars and doll-pedestrians could be positioned on the model to create road situations comparable to those encountered in the real traffic environment. The model was placed on a large table chosen to suit the stature of the children.

The roadside training group was trained in the real traffic environment in the streets near their school. Care was taken to ensure that the road locations and situations developed for the tabletop model group were similar to those used in the real world, although they were not intended to be identical. Both included bends, junctions, parked cars and other zones of diminished visibility.

\section{General design}

Childten were both tested and trained individually by the same experimenter. All children were pretested on three separate occasions to ascertain there were no major differences between them prior to training. The pre-tests also established a baseline against which the effects of training could be judged. Each group then underwent six training sessions at a rate of roughly one a week, either on the tabletop model or in the traffic environment, with a brief test in the middle for evaluation purposes. Training was immediately followed by three sessions of post-testing (Post-test 1). A further group of post-tests (Posttest 2) was run 63 days after Post-test 1 to assess the longer-term effects of training. Finally, 10 of the 16 children were retested eight months after termination of the programme (Post-test 3). They were compared to a control group of 10 Primary 2 children from the same school who had undergone no training whatever. The mean ages of the children at the time of this final post-test were: trained group: 6 years 4 months; control group: 6 years 2 months. The general experimental design is shown schematically in Fig. 2.
PRE-TESTS
POST-TEST 1
POST-TEST 2
POST-TEST 3
(3 sessions)
(3 sessions)
(3 sessions)
(3 sessions)

$\begin{array}{lc}\text { TRAINING } & \text { INTERVAL } \\ \text { (6 sessions) } & \text { (63 days) }\end{array}$

INTERVAL
( 8 months from
end of training)

Figure 2. Schematic representation of the layout of Expt 2.

Pre- and post-tests. The three pre-tests each took the same form as the tests employed in Expt 1. Thus, each child was tested at four locations, with four judgements to be made at each, yielding 16 judgements in each of the three sessions. Children received no feedback of any kind during these test sessions so that there was no bias on subsequent training. All tests were conducted in the road environment, irrespective of whether training was by the roadside or on the tabletop model. The tests also took place in a completely different area from the training so that the real traffic group would not have the advantage of familiarity with the testing environment. The same tests were readministered immediately after termination of the training programme (Post-test 1). They were repeated 63 days later (Post-test 2) and again eight months after termination of training (Post-test 3 ). The scoring procedure was as in Expt 1.

\section{Training}

The children were trained individually on either the tabletop model or at the roadside. Training concentrated on the two main errors committed by 5-year-olds in Expt 1 and previous research. These were failing to recognize dangerous sites and selecting the most direct route to the destination as safest.

The aim of the training procedure was to get the children to appreciate the danger posed by poor visibility, complex road layouts and lengthy excursions across the road. We wanted them to discover 
principles and, at all costs, we wanted to avoid simply giving drills or lists of 'dos' and 'don'ts'. Rather, our aim was to improve the child's conceptual understanding so that they could deal flexibly with a wide range of situations, including ones which they had not yet encountered. To achieve this, we tried to guide the children's reasoning so that they would discover the principles through their own rather than through our reasoning. Our procedure was as follows.

The importance of visibility. Children frequently considered sites offering poor visibility to be safe. We encouraged the child to discover the error of these decisions by taking them through the following steps:

(1) First the child was asked if specific approaching vehicles could be seen from the point they were occupying. They were asked about how well the vehicles could be seen, the point at which they first came into view and so forth. Then they were questioned about other objects that were invisible or difficult to see from the point currently being occupied. In this way, we tried to bring to the child's attention that their vision was restricted at that location.

(2) The child was then asked why they could not see the approaching traffic or the object. Here, the children were encouraged to realize that it was the position they were occupying that made it difficult to see.

(3) The experimenter then invited the child to do something that might improve visibility. This introduced the notion that it might be necessary to move.

In most cases, children could be encouraged to find their own way to this point. If the child moved to a different site, the experimenter went through the same procedure to ensure it had not been chosen purely at random.

Where the above process was unsuccessful, the experimenter intervened more directly as follows:

(4) The experimenter explained that the approaching traffic could not be seen, for example, because of the parked car or other obstruction limiting the child's view. It was explained that it would be safer to find a place where a clear view of the road was possible. The experimenter then encouraged the child to find another site which would be more suitable.

(5) Where a child still failed to understand, the experimenter demonstrated an appropriate choice. They then moved to another location.

Choosing a route. To improve the routes that children chose, the experimenter proceeded as follows. Where, for example, a diagonal route was selected:

(1) The experimenter explained that the diagonal toute was a long way to go and asked why this might be dangerous. The child was thus encouraged to realize that a car might come before crossing was complete. They were then asked to choose a route which would not keep them on the road for too long.

(2) The children were questioned extensively to get them to discover the danger of being on the road too long. However, some children found this difficult and persisted in maintaining that the diagonal route was safe. If this continued too long, the experimenter explained the danger to them and asked how the problem might be remedied. This often evoked suggestions such as walking along the pavement to get closer to the destination before crossing

(3) Where a child still failed to understand, the experimenter showed an acceptable solution. They then moved to a new location.

In addition to these steps, we also emphasized the importance of stopping at the kerb to look and listen for traffic once an appropriate site had been found. Of course, the process of finding a safe site implicitly implies appreciating the possible whereabouts of nearby traffic, so such awareness is already intensified by the process of safe site selection.

Appropriate behaviour was positively reinforced both verbally and also with rewards of either gold or silver stars which the children collected in a small book.

Both groups completed six training sessions lasting approximately 30 minutes. Both were exposed to the same number of problems in each test, ensuring that the tabletop group did not benefit from extra training due to not having to walk from site to site. Roughly halfway through the training programme, the children were briefly retested. This was done simply as a monitoring exercise to provide the experimenter with some feedback for the remainder of the programme. 
Table 2 shows the mean proportion of routes falling into the different safety categories as a function of training method and test phase. As in Expt 1, analysis is based on the proportion of 'safe' routes produced by each group.

Table 2. Mean proportion of routes falling into each safety category as a function of training group and testing phase (standard deviations in parentheses)

\begin{tabular}{|c|c|c|c|c|c|c|}
\hline \multirow[b]{3}{*}{ Safety categories } & \multicolumn{6}{|c|}{ Training groups } \\
\hline & \multicolumn{3}{|c|}{ Real traffic test phases } & \multicolumn{3}{|c|}{ Tabletop model test phases } \\
\hline & PT & PT1 & PT2 & PT & PT1 & PT2 \\
\hline Very unsafe & $\begin{array}{c}.05 \\
(.03)\end{array}$ & $\begin{array}{c}.01 \\
(.01)\end{array}$ & $\begin{array}{c}.14 \\
(.34)\end{array}$ & $\begin{array}{c}.04 \\
(.32)\end{array}$ & $\begin{array}{c}.05 \\
(.08)\end{array}$ & $\begin{array}{c}.04 \\
(.04)\end{array}$ \\
\hline Unsafe & $\begin{array}{c}.22 \\
(.18)\end{array}$ & $\begin{array}{c}.27 \\
(.29)\end{array}$ & $\begin{array}{c}.34 \\
(.34)\end{array}$ & $\begin{array}{c}.43 \\
(.32)\end{array}$ & $\begin{array}{c}.23 \\
(.27)\end{array}$ & $\begin{array}{c}.37 \\
(.34)\end{array}$ \\
\hline More safe & $\begin{array}{c}.11 \\
(.10)\end{array}$ & $\begin{array}{c}.00 \\
(.00)\end{array}$ & $\begin{array}{c}.06 \\
(.10)\end{array}$ & $\begin{array}{c}.07 \\
(.09)\end{array}$ & $\begin{array}{c}.02 \\
(.03)\end{array}$ & $\begin{array}{c}.06 \\
(.04)\end{array}$ \\
\hline Safe & $\begin{array}{c}.13 \\
(.20)\end{array}$ & $\begin{array}{c}.72 \\
(.28)\end{array}$ & $\begin{array}{c}.50 \\
(.36)\end{array}$ & $\begin{array}{c}.07 \\
(.16)\end{array}$ & $\begin{array}{c}.70 \\
(.30)\end{array}$ & $\begin{array}{c}.54 \\
(.34)\end{array}$ \\
\hline
\end{tabular}

$\mathrm{PT}=$ Pre-test. PT $1=$ Post-test $1 . \mathrm{PT} 2=$ Post-test 2.

The effect of training method (tabletop versus roadside); test phase (Pre-/Post-test 1 and Post-test 2); and sex on route selection were examined by means of a three-way ANOVA. The results yielded no significant main effects of training method or sex. However, the main effect of test phase was highly significant $(F(2,24)=35.97$, $p<.001)$. None of the interactions reached significance.

Follow-up tests using the Newman-Keuls procedure on the children's performance in the three test phases showed that they chose more safe routes in both Post-test 1 and Post-test 2 than in the pre-test ( $p<.01$ in both cases). The comparison between Post-test 1 and Post-test 2 was also significant $(p<.05)$.

As only 10 of the children were available for Post-test 3, this was analysed separately. Results for the two groups are shown in Table 3 .

Comparison of the trained and control groups shows that the trained group selected more 'safe' routes than the untrained controls $(t(18)=3.01, p<.01)$. In addition, we compared the performance of the trained group with their own performance in earlier tests. These are shown in Table 4.

It can be seen that the decline observed after Post-test 2 continued at a slower rate. However, whilst the difference between Post-tests 1 and 3 is significant $(t(9)=3.75$, $p<.01)$, the difference between Post-test 2 and Post-test 3 is not $(t(9)=.66$, n.s.). 
Table 3. Mean proportion of routes falling into the different safety categories for trained and control groups (standard deviations in parentheses)

\begin{tabular}{|c|c|c|}
\hline \multirow[b]{2}{*}{ Safety category } & \multicolumn{2}{|c|}{ Groups } \\
\hline & Trained & Control \\
\hline Very unsafe & $.01(.01)$ & $.14(.31)$ \\
\hline Unsafe & $.45(.27)$ & $.73(.29)$ \\
\hline More safe & $.16(.18)$ & $.01(.03)$ \\
\hline Safe & $.38(.23)$ & $.12(.15)$ \\
\hline
\end{tabular}

Table 4. Mean proportions of routes falling into the different safety categories as a function of test phase (standard deviations in parentheses)

\begin{tabular}{lcccc}
\hline & \multicolumn{5}{c}{ Test phase } \\
\cline { 2 - 5 } Safety category & PT & PT1 & PT2 & PT3 \\
\hline Very unsafe & .50 & .04 & .13 & .01 \\
& $(.29)$ & $(.07)$ & $(.30)$ & $(.01)$ \\
Unsafe & .29 & .26 & .33 & .45 \\
& $(.27)$ & $(.29)$ & $(.29)$ & $(.27)$ \\
More safe & .11 & .01 & .07 & .16 \\
& $(.12)$ & $(.02)$ & $(.08)$ & $(.18)$ \\
Safe & .08 & .69 & .50 & .38 \\
& $(.15)$ & $(.32)$ & $(.32)$ & $(.23)$ \\
\hline
\end{tabular}

PT $=$ Pre-test. PT1 $=$ Post-test 1. PT2 $=$ Post-test 2. PT3 $=$ Post-test 3 .

Thus, whilst a deterioration in performance occurred in the short term (i.e. in the two months between Post-tests 1 and 2), no further significant deterioration seems to have taken place in the ensuing six months. The difference between the trained and control groups suggests that this was not merely offset by a general improvement due to age. It would appear, then, that even one short training programme at age 5 can have beneficial effects that are maintained over a considerable period. Of course, more intensive or frequent training could be expected to further improve and maintain the skill level attained.

\section{Discussion}

The purpose of this study was to investigate the effect of two kinds of training on the errors made by 5 -year olds in deciding where to cross the road. The results suggest 
that both training methods substantially improved their behaviour, making them effectively like older, more experienced children. In fact, the trained 5-year-olds in Post-test 1 performed more like control 11-year-olds (see Expt 1) than untrained 5-year-olds. Even after the decline seen in Post-tests 2 and 3, they were still performing more like 9-year-olds than 5-year-olds. No difference emerged between those trained at the roadside and those trained on the tabletop model, nor were any sex differences apparent.

The equal effectiveness of the tabletop model and the roadside training is particularly interesting, especially in relation to the claim sometimes made that the former does not work. It may be that the crucial issue is not so much the method per se, but what the method is trying to teach that determines whether or not improvement is seen. Skills such as crossing at an intersection (van Schagen \& Rothengatter, 1986) or the safe place selection studied here, may well benefit from tabletop methods. For other skills, however, the tabletop model seems unlikely to be helpful. For example, it seems unlikely that the visual timing skills studied by Lee and his colleagues would benefit from this approach. Here, a practical approach in the real environment would appear to be essential.

It must also be conceded that even the tabletop group in this experiment received some prior exposure to the roadside environment during the pre-tests. Indeed, we felt it was important for the children to see the correspondence between the situations they were experiencing on the model and real-life equivalents. Stressing the links between a classroom technique and its reference is, of course, an important element in all educational experience and one we certainly did not wish to eliminate here. It would appear, however, that at most only a small amount of such priming is necessary for the tabletop training to be as effective as experience received wholly in traffic.

Whilst the training achieved quite impressive improvements that were substantially maintained even after a two-month lapse, there was nevertheless a significant decline between Post-test 1 and Post-tests 2 and 3. This shows that training is limited if it is restricted to one-off efforts, even where the short-term gains are known to be substantial. Some form of updating is clearly desirable to keep the children 'tuned up'. This point, of course, has implications for all current road safety education which is extremely intermittent in nature.

\section{GENERAL DISCUSSION}

The results of the present study show, first of all, how valuable diagnostic studies can be to the development of training schemes. The results of Expt 1 showed specific errors committed by 5 -year-olds relative to older groups and threw light on the factors responsible for these differences. The substantial improvement we obtained following training suggests that children can be trained to behave like more experienced pedestrians if the skills requiring development are properly defined. The results do not support the thesis that such skills are heavily dependent on maturational factors as often assumed in road safety research: instead, development can be accelerated through appropriate training. The relative failure of current approaches reflects, we believe, a failure to recognize the skills required for 
participation in traffic and a corresponding failure to develop appropriate training programmes. Road safety research needs to take a hard look at its aims and assumptions if more effective methods and results are to be obtained.

One problem to which we have already drawn attention is that road safety education in Great Britain is seen mostly in terms of simple rules such as the Green Cross Code (Grayson, 1981). The problems with such rule-orientated approaches are well known (see for example, Rothengatter, 1981a). Our approach, aimed at giving children appropriate experience from which to learn for themselves, seems to fit with much current evidence that such practical experience is superior to rule-bound approaches (Thomson, 1991). We believe such approaches hold the key to advances in road safety training.

Whilst the results of this study are encouraging, there is no doubt that a large-scale implementation of the training scheme would be required together with further research into the optimum duration and frequency of training for beneficial effects to be maintained into the long term. Given the apparent vulnerability of young children in selecting places at which to put the Green Cross Code into action, such studies would already seem to be overdue. We hope to report on such questions in the near future.

\section{Acknowledgements}

This study was supported by ESRC grant X202252001, financed by General Accident Insurance through its Road User Behaviour Initiative.

\section{References}

Ampofo-Boateng, K. (1987). Children's perception of safety and danger on the road. Unpublished doctoral dissertation, University of Strathclyde.

Ampofo-Boateng, K. \& Thomson, J. A. (1990). Child pedestrian accidents: A case for preventive medicine. Health Education Research: Theory and Practice, 5, 265-274.

Ampofo-Boateng, K. \& Thomson, J. A. (1991). Children's perception of safety and danger on the road. British Journal of Psychology, 82, 487-505.

Dean, C. (1981). The organisation of road safety in Britain. In H. C. Foot, A. J. Chapman \& F. M. Wade (Eds), Road Safety Research and Practice. Eastbourne: Praeger.

Deschamps, J. P. (1981). Prevention of Traffic Accidents in Cbildbood. Copenhagen: WHO.

Foot, H. C., Chapman, A. J. \& Wade, F. M. (1982). Pedestrian accidents: General issues and approaches. In A. J. Chapman, F. M. Wade \& H. C. Foot (Eds), Pedestrian Accidents. Chichester: Wiley.

Foot, H. C. (1985). Boys will be boys? Safety Education, 1, 6-8.

Gardner, P. L., Rowley, G. L., Bowen, R., Hayman, A. \& Fyfield, J. A. (1986). Measuring the Outcomes of Road Safety Education. Australia: Monash University Press.

Grayson, G. B. (1981). The identification of training objectives: What shall we tell the children? Accident Analysis and Prevention, 13, 169-173.

Howarth, C. I. \& Repetto-Wright, R. (1978). Measurement of risk and the attribution of responsibility for child pedestrian accidents. Safety Education, 144, 10-13.

Lee, D. N., Young, D. S. \& McLaughlin, C. M. (1984). A roadside simulation of road crossing for children. Ergonomics, 27, 1271-1281.

Molen, H. H., van der (1983). Pedestrian ethology. Doctoral dissertation, University of Groningen, The Netherlands. 
O'Donoghue, J. (1988). Pedestrian casualties. Road Accidents Great Britain 1987: The Casualty Report. London: HMSO.

Rothengatter, T. (1981a). Modifying traffic behaviour or the child pedestrian by educational countermeasures; Review of current research and problems of implementation. In S. J. Yerrell (Ed.), Transport Research for Social and Economic Progress, 4. Aldershot: Gower.

Rothengatter, T. (1981b). Traffic education for young children. In H. C. Foot, A. J. Chapman \& F. M. Wade (Eds), Road Safety Research and Practice. Eastbourne: Praeger.

Rothengatter, T. (1984a). A behavioural approach to improving traffic behaviour of young children. Ergonomics, 27, 147-160.

Rothengatter, T. $(1984 b)$. The role of media in road safety education of children. British Journal of Developmental Psychology, 2, 157-165.

Routledge, D. A., Repetto-Wright, R. \& Howarth, C. I. (1974). The exposure of young children to accident risk as pedestrians. Ergonomics, 17, 623-638.

Sandels, S. (1975). Cbildren in Traffic. London: Elek.

Schagen, I, van \& Rothengatter, J. A. (1986). Crossing at intersections: The development of an educational programme module for primary school children. Traffic, Planning and Safety, 13, 50-56.

Singh, A. (1982). Pedestrian education. In A. J. Chapman, F. M. Wade, \& H. C. Foot (Eds), Pedestrian Accidents. Chichester: Wiley.

Thomson, J. A. (1991). The Facts About Child Pedestrian Accidents. London: Cassell.

Tight, M. (1991). Child pedestrian accidents. Inroads: Journal of the Institute of Road Safety Officers, 12, 31-35.

Vinje, M. P. (1981). Children as pedestrians: Abilities and limitations. Accident Analysis and Prevention, 13, 225-240.

Young, D. S. \& Lee, D. N. (1987). Training children in road crossing skills using a roadside simulation. Accident Prevention and Analysis, 19, 327-341.

Received 15 November 1990; revised version received 27 September 1991 


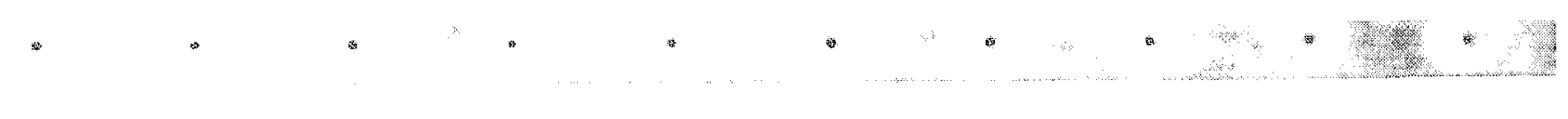

' 